\title{
Combination of MSAT and Korean Medicine for Managing Foot Drop Due to Lumbar Disc Herniation: Case Report
}

\author{
Ji-won Park ${ }^{1}$, Wu-Jin Jeong ${ }^{1}$, Hyo-Seung Huh ${ }^{1}$, Hae-Won Hong ${ }^{1}$, Ji-eun Koo ${ }^{2}$ \\ 1 Department of Acupuncture \& Moxibustion Medicine, Daejeon Jaseng Hospital of Korean Medicine, \\ ${ }^{2}$ Department of Rehabilitation Medicine of Korean Medicine, Daejeon Jaseng Hospital of Korean Medicine \\ 족하수 환자의 복합 한의진료 경과 및 삶의 질 변화: 증례보고 \\ 박지원 $^{1(1)} \cdot$ 정우진 $^{1(1)} \cdot$ 허효승 $^{1(1)} \cdot$ 홍혜원 $^{1(1)} \cdot$ 구지은 $^{2}$ \\ ${ }^{1}$ 대전자생한방병원 침구의학과, ${ }^{2}$ 대전자생한방병원 한방재활의학과
}

Foot drop due to lumbar disc herniation is perceived to be an indication for surgery. A 44-year-old male presented with motor deficit in left ankle dorsiflexion along with radiating pain and paraesthesia. Motion Style Acupuncture Therapy (MSAT) was administered on the left side every other day. Acupuncture and Chuna were performed daily. Herbal medicine was taken 3 times a day. His symptoms rapidly improved throughout treatment, verified by decreased Numeric Rating Scale (NRS), Oswestry Disability Index (ODI), increased 5-level EuroQol-5 Dimension (EQ-5D-5L) scores, and improved motor grades. We suggest that a combination of MSAT with traditional Korean medicine could be a favorable option for foot drop in LDH patients in terms of rapid pain reduction and the improvement of quality of life.

Key words : foot drop, MSAT, lumbar disc herniation, Korean medicine

\section{Introduction}

Foot drop is characterized by weakness of the ankle dorsiflexors resulting in the inability to or difficulty in lifting the forefoot contributing to considerably impaired mobility and general health ${ }^{1}$. Among the various disorders that lead to foot drop, the most common cause is lumbar degenerative disease. Lower back pain, radiating pain, sensory defects, and weakness in the distribution of nerve roots are primary symptoms of Lumbar Disc Herniation (LDH $)^{2)}$. However, foot drop due to $\mathrm{LDH}$ is a rare event and there is insufficient research clarifying the clinical features, risk factors, natural history, and prognosis ${ }^{3)}$.

At present, patients with motor deficit resulting from $\mathrm{LDH}$ are mostly treated by surgery, but there is inadequate evidence to certify the superiority of surgery over conservative treatments ${ }^{4}$. In this case report, the patient was also recommended surgery because his persistent pain was refractory to pain medication and he developed motor deficit ${ }^{5}$. We administered Motion Style Acupuncture Therapy (MSAT) combined with traditional Korean medicine to enhance the effectiveness of the traditional acupuncture treatment. The

Received July 16, 2021, Revised September 6, 2021, Accepted September 8, 2021

Corresponding author: Ji-won Park

Department of Acupuncture \& Moxibustion Medicine, Daejeon Jaseng Hospital of Korean Medicine, 58 Munjeong-ro, 48 Beon-gil, Seo-gu, Daejeon 35262, Korea

Tel: +82-42-1577-0007, Fax: +82-42-610-0415, E-mail: lilybells93@jaseng.org

(C) This is an open access article distributed under the terms of the Creative Commons Attribution Non-Commercial License (http://creativecommons.org/licenses/ by-nc/4.0) which permits unrestricted non-commercial use, distribution, and reproduction in any medium, provided the original work is properly cited. 
patient's personal information and medical records were obtained from the Institutional Review Board of Jaseng Korean medical hospital (IRB file no.: 2021-06-009).

\section{Case}

A 44-year-old male, an office worker, with the chief complaints of sciatic pain (lower back, left buttock, left lateral thigh and calf), decreased sensation in the left calf, and muscle weakness was admitted to a traditional Korean Medicine Hospital on November 23, 2020. He had previously visited an orthopedic clinic and had been prescribed medication to manage the pain in his low back and left lower leg that had started around November 4, 2020. He had no symptoms of radicular weakness at the onset. His pain did not alleviate despite taking medication but worsened over time, and numbness of the left leg and the inability of left ankle dorsiflexion began to develop around November 12, 2020. He revisited the clinic and lumbar magnetic resonance imaging (MRI) was done for further evaluation. The lumbar MRI revealed broad based disc herniation at the L3-4 level and disc extrusion at the L4-L5 level compressing the left nerve root of L5 (Fig. 1). In the presence of neurological signs

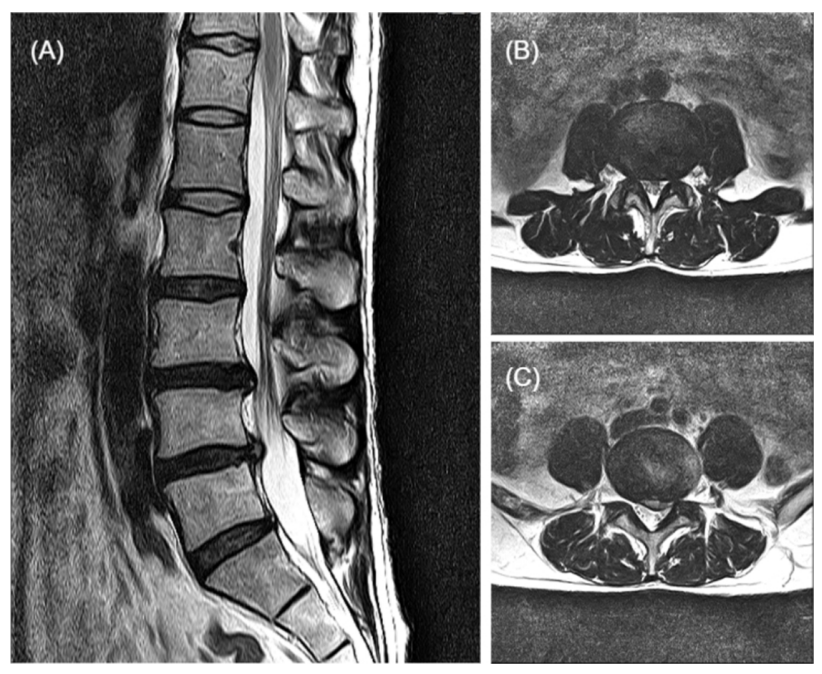

Fig. 1. Magnetic resonance imaging (November 13th, 2020). (A) Mid-sagittal MRI showed LDH at L3-5. (B) Axial MRI of L3-L4 showed broad based disc herniation. (C) Axial MRI of L4-5 showed disc extrusion and left L5 nerve root compression. and severe pain that persisted despite medicinal treatment, he was recommended surgical treatment. However, he refused to have the surgery concerned by possible complications such as incomplete decompression and recurrent disc herniation, and decided to take conservative treatment.

\section{Physical Examination at Admission}

On the first day of his visit to our outpatient department, his self-reported overall pain score was 7/10 on an 11-point numeric rating scale (NRS). Neurological examinations showed preserved plantar flexion but weakness of left ankle dorsiflexion (grade 3/5) using manual muscle testing (MMT). Along the left anterolateral calf he showed decreased sensation by pin prick test. Both knee and ankle reflexes were intact and neurogenic claudication was negative. The Bragard and Laseque tests were negative and straight leg raising tests showed positive at 70 degrees. Tests for walking on the toe/heel were conducted and he could stand on the toes and heel of his right foot, but could only stand on the toes and not the heel of his left foot.

\section{Treatment Methods}

\section{1) Acupuncture Treatment}

(1) Conventional Acupuncture: The patient received acupuncture treatment in the lower back and the lower left extremity. The acupoints used in the present study include Shinsu (BL23), Daejangsu (BL25), Charyo (BL32), Jilbyeon (BL54), Wijung (BL40), Hwando (GB30), and Hyeonjong (GB39). Disposable sterile acupuncture needles $(0.25 \mathrm{~mm} \times 30 \mathrm{~mm}$; Dong-bang Acupuncture, SeongNam, Korea) were used. Electroacupuncture $(1 \sim 25 \mathrm{~Hz})$ was applied at 2 acupuncture points using a low frequency treatment device (STN-330 Stratek, Anyang, Korea) and all the needles were retained for 15 minutes.

(2) MSAT: The patient is instructed to lie in a supine position with their lower legs exposed. Before inserting the acupuncture needles, the difference in left and right ankle dorsiflexors is examined against the examiner's resistance at the same time and acupuncture is performed on the side with muscle weakness. After sterilizing with ethanol around the 
needling points, disposable sterile acupuncture needles (0.25 mm×30 mm; Dong-bang Acupuncture, SeongNam, Korea) are used. The needling points of the tibialis anterior muscle (TA) are Joksamni (ST36), Sanggeoheo (ST37), and Hageoheo (ST39).

While the needles are being inserted, the patient is asked to bend and stretch their ankle repeatedly to see the needles move. After removing the needles, the doctor stretches the patient's knee and hip muscles and then, evaluates the muscle strength of the affected TA again.

2) Herbal medicine: Cheongpa-jeon, Cheongshinbaro- hwan, and Gwanjul-go were administered to the patient for their anti-inflammation, nerve regeneration, cartilage protection, and pain management properties (Table 1).

3) Chuna therapy: Chuna therapy was administered once a day. He received myofascial release and muscle energy technique in the lumbar, pelvis, and pubis area, with hip joint articulation.

\section{Progress note}

Before admission, the patient initially rated his low back pain, left buttock pain, and radiating pain as 7/10 on the Numeric Rating Scale (NRS) and the Oswestry Disability Index (ODI) score and Korean version of the 5-level EuroQol5 Dimension (EQ-5D-5L) score were 8.89 and 0.73, respectively $^{6-8)}$. As treatment continued, his clinical symptoms started to alleviate. On day 8 of his admission, he reported that the pain and numbness in his lower left extremity had significantly improved to $1 / 10$. On day 10 of his admission, he no longer required his medication (Exoperin Tab 50 mg, Monimer Tab 350 mg, Polybutine SR Tab 300 mg, and Stillen 2X Tab $90 \mathrm{mg}$ ) prescribed before his admission. On day 17 of his

Table 1. Herbal medicine prescriptions administered to the patient

\begin{tabular}{|c|c|}
\hline Herbal prescription & Herbal medicine components \\
\hline Cheongpa-jeon & $\begin{array}{l}\text { Lasiosphaera Seu Calvatia } 11.25 \mathrm{~g} \text {, Acanthopanacis Cortex·Eucommiae Cortex Ledebouriellae } \\
\text { Radix·Achyranthis Radix·Cibotii Rhizoma } 7.5 \mathrm{~g} \text {, Atractylodis Rhizoma alba·Amomi Semen·Geranii } \\
\text { Herba·Scolopendra } 3.75 \mathrm{~g} \text {, Glycyrrhizae Radix } 2.5 \mathrm{~g} \text {, Zingiberis Rhizoma } 1.875 \mathrm{~g} \text {. }\end{array}$ \\
\hline Cheongshinbaro-hwan & $\begin{array}{l}\text { Rehmanniae Radix } 0.208 \mathrm{~g} \text {, Mel } 0.104 \mathrm{~g} \text {, Pachyma hoelen rumphius } 0.052 \mathrm{~g} \text {, Ginseng Radix } 0.026 \mathrm{~g} \text {, Glue } \\
\text { of Cervi Parvum Cornu and Cervi Cornu } 0.022 \mathrm{~g} \text {, Atractylodis Rhizoma alba } 0.017 \mathrm{~g} \text {, Achyranthis Radix } \\
0.013 \mathrm{~g} \text {, Cibotii Rhizoma'Eucommiae Cortex Cibotii Rhizoma, Gallbladder of Bos taurus L. } 0.009 \mathrm{~g} \text {, Gelatinum } \\
0.006 \mathrm{~g} \text {, Achyranthis Radix Ledebouriellae Radix Acanthopanacis Cortex Scolopendra } 0.004 \mathrm{~g} \text {, } \\
\text { Cheongshinbaro-hwan dried extract } 0.5 \mathrm{~g}\end{array}$ \\
\hline Gwanjul-go & $\begin{array}{l}\text { Poria cocos (Schw.) Wolf, } 1.634 \mathrm{~g} \text {, Ginseng Radix Alba, } 0.817 \mathrm{~g} \text {, Achyranthes bidentata Bl., } 0.204 \mathrm{~g} \text {, Asini } \\
\text { Gelatinum, } 0.102 \mathrm{~g} \text {, Rehmanniae Radix, } 3.268 \mathrm{~g} \text {, Cervi Cornus Colla, } 0.34 \mathrm{~g} \text {, Mel, } 1.634 \mathrm{~g}\end{array}$ \\
\hline
\end{tabular}

Low back and left buttock pain

Radiating pain

10

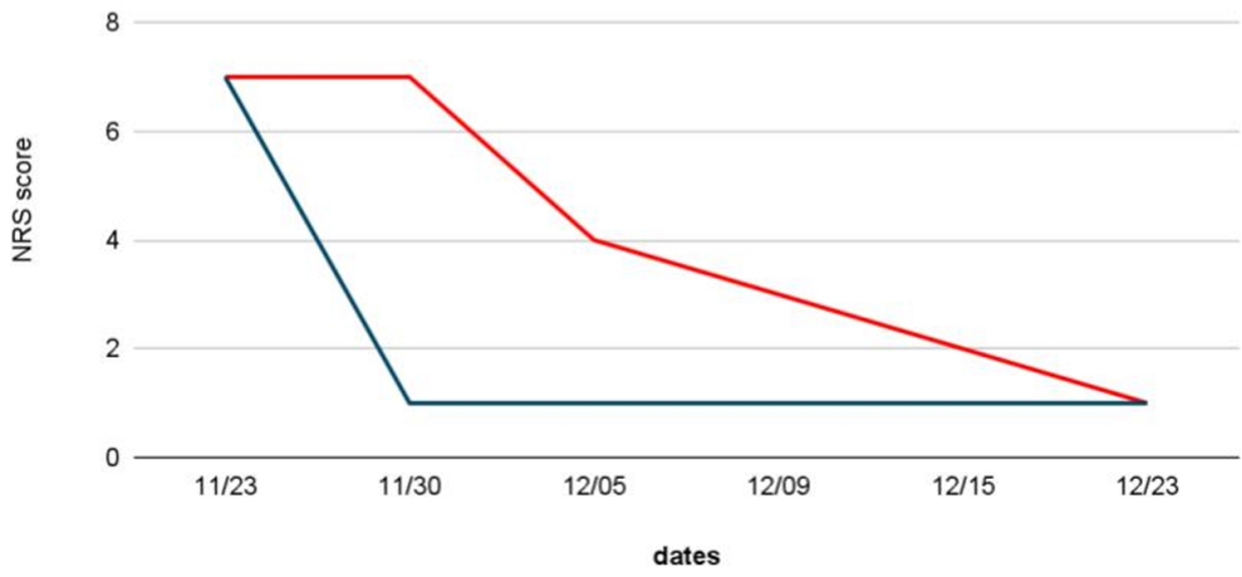

Fig. 2. Changes in the NRS score of low back/left buttock pain and radiating pain. NRS : numeric rating scale. 
admission, he reported noticeable restorement of hypoesthesia in his lower left extremity and further improvement of the pain's intensity (3/10) (Fig. 2). Evaluation of left ankle dorsiflexion was done during MSAT treatment every other day. On December 12, 2020, the muscle strength of left ankle improved to $4 / 5$ and restored to full extent on December 19 ,
2020 (Fig. 3). On December 31, 2020, he was discharged from the hospital since he had no difficulty with daily activities such as walking, standing, and sitting. At the end of the treatment, EQ-5D (0.899), ODI (6.67) scores were reevaluated (Fig. 4).

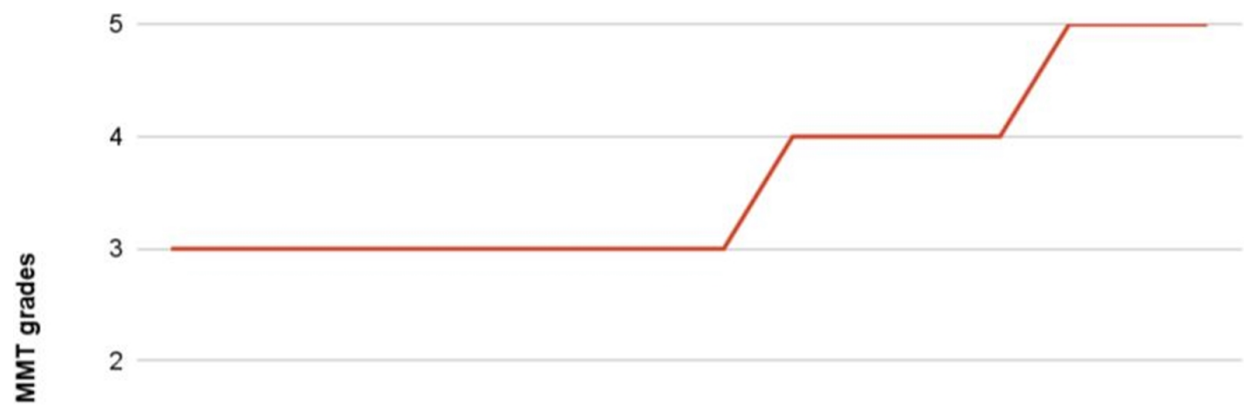

1

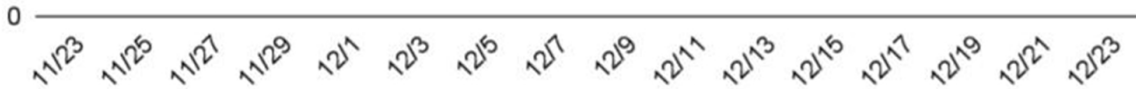
dates
Fig. 3. Changes in MMT of left ankle dorsiflexion. MMT : manual muscle testing.

\begin{tabular}{|c|}
\hline $\begin{array}{l}2020.11 .04 \\
\text { The patient began to experience pain in the low back and left } \\
\text { lower leg. }\end{array}$ \\
\hline $\begin{array}{l}2020.11 .12 \\
\text { His pain worsened and numbness of the left leg and inability of } \\
\text { left ankle dorsiflexion began to develop. } \\
\text { L-spine MRI was done revealing L3-4-5 disc herniation. } \\
\text { He was recommended surgical treatment but refused. }\end{array}$ \\
\hline
\end{tabular}

\subsubsection{0}

"The numbness in the back of the left thigh has improved by almost $90 \%$. The feeling of having less power with the left ankle when walking is improving."

His pain and numbness of the left lower extremity significantly improved.

Low back and left buttock pain: NRS7, Radiating pain: NRS1

\subsubsection{9}

"I think the sensation of the left leg is well on the way to recovery. Compared to the right leg, about $90 \%$ of my sensation returned." Noticeable restorment of hypoesthesia in the left lower leg and further improvement of the pain intensity

Low back and left buttock pain: NRS3, Radiating pain: NRS

2020.12.23

"I don't really feel any pain in the lower back and left leg and it doesn't require much effort to move my ankle.

Low back and left buttock pain: NRS1, Radiating pain: NRS1 ODI:6.67, EQ-5D:0.899, left ankle dorsiflexion:5/5

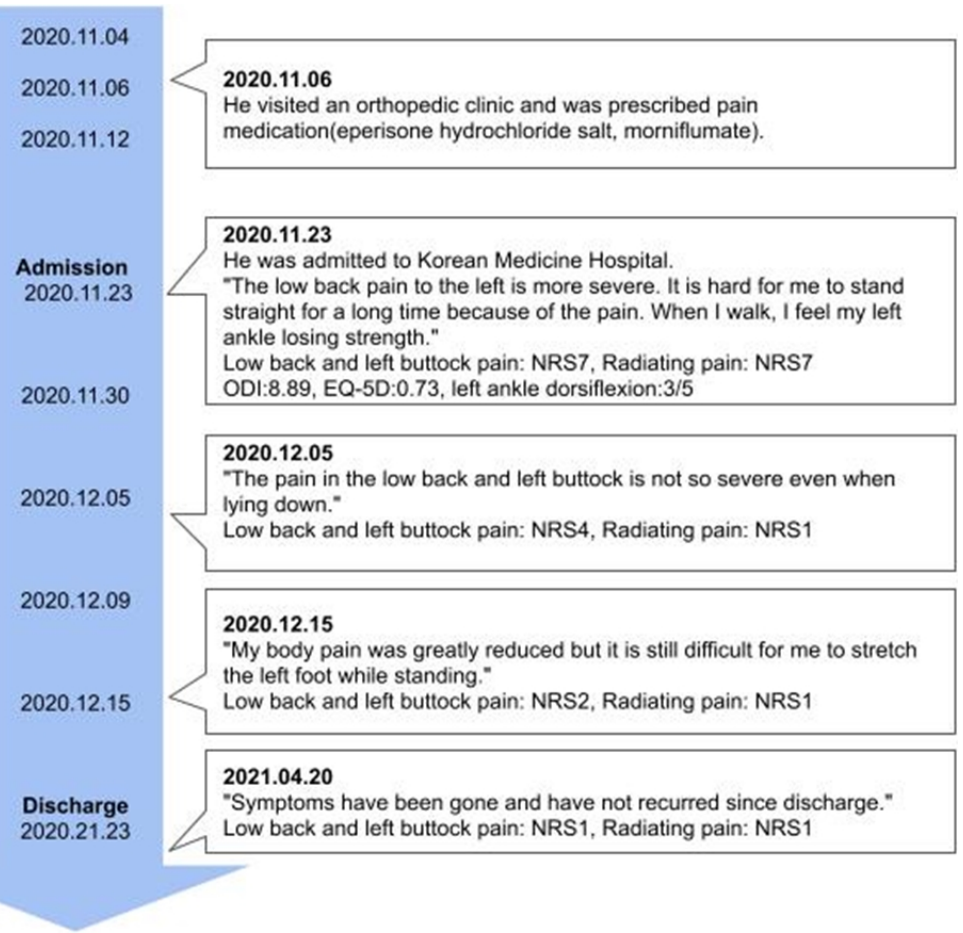

Fig. 4. Timeline of patient history and clinical symptoms. 


\section{Discussion}

Lumbar disc herniation is the most common degenerative abnormality of the lumbar spine resulting in weakness presenting in a myotomal distribution. However, foot drop due to $\mathrm{LDH}$ is relatively infrequent and presents a severe motor deficit. Surgical treatments are useful, but surgical treatment has a higher risk of complications" and does not show superiority to conservative treatment in the midterm and longterm $^{10)}$. Conservative management provides pain control for almost $90 \%$ of patients after 3 months ${ }^{11)}$. Acupuncture is also an effective means in the conservative treatment of $\mathrm{LDH}$ and shown to be more advantageous than lumbar traction, and ibuprofen ${ }^{12)}$.

MSAT refers to a relatively novel method which has been reported to be a valuable means to derive satisfactory treatment results in terms of instantaneous pain reduction and functional improvement ${ }^{13}$. MSAT has a distinction from traditional acupuncture in that the needles are inserted into the body followed by either passive or active movement of the patient's body. The effectiveness of MSAT has been recognized in clinical fields in South Korea and China, of which the use has been continuously increasing ${ }^{14}$. We administered TA MSAT in addition to conventional treatment to shorten recovery. Weakness in ankle-dorsiflexion is mainly caused by disc prolapse at the $\mathrm{L} 4-\mathrm{L} 5$ level $^{15)}$ because fibers from the L5 nerve root comprise the peroneal nerve which innervates ankle dorsiflexors. TA MSAT is so called based on neurophysiological knowledge that among the ankle dorsiflexors, the tibialis anterior is the main dorsiflexor muscle of the foot ${ }^{10}$.

The mechanism of MSAT has not been fully elucidated, thereby we propose hypotheses. First, MSAT might have an advantage from a psychological point of view. When performing TA MSAT, the practitioner compares the degree of post-treatment weakness to pre-treatment weakness at each procedure which helps the patient to realize how much strength has actually been restored. Repetitive appraisals might help relieve the somatising tendency and correct the patient's negative perception causing adversity ${ }^{17}$. Second,
MSAT focuses on immediate analgesic effects. Moving the patient's body with retained needles strongly stimulates the muscles and this stimulation can induce an immediate analgesic effect by extensively activating the brain ${ }^{18}$. The immediate analgesic effect can motivate the patient to receive long-term treatments or be open to other forms of physiotherapies ${ }^{19)}$.

This study is the first in literature to report TA MSAT and suggests that TA MSAT can elicit rapid pain reduction and health improvement in a patient with foot drop. Thereby, we suggest this study sheds light on the effectiveness of MSAT to treat foot drop due to LDH.

Some limitations of this case report should be addressed. First, this study is a single case for results to be generalized. Second, the practice of MSAT is still primarily based on personal experiences and very few studies have been conducted to investigate its efficacy and safety ${ }^{13,20)}$. Third, the sole therapeutic effect of TA MSAT for the current case could not be separated from other interventions. Thus further randomized, controlled trials are required to provide additional evidence to confirm the effectiveness of MSAT.

\section{Acknowledgement}

None.

\section{Funding}

None.

\section{Data availability}

The authors can provide upon reasonable request. 


\section{Conflicts of interest}

The authors have declared that no conflicts of interest exists.

\section{References}

1. Westhout FD, Paré LS, Linskey ME. Central causes of foot drop: rare and underappreciated differential diagnoses. J Spinal Cord Med. 2007 ; 30(1) : 62-6. https://doi.org/10.1080/10790268. 2007.11753915

2. Vroomen PC, de Krom MC, Wilmink JT, Kester AD, Knottnerus JA. Diagnostic value of history and physical examination in patients suspected of lumbosacral nerve root compression. J Neurol Neurosurg Psychiatry. 2002 ; 72(5) : 630-4. https://doi.org/10. 1136/jnnp.72.5.630

3. Ghahreman A, Ferch RD, Rao P, Chandran N, Shadbolt B. Recovery of ankle dorsiflexion weakness following lumbar decompressive surgery. J Clin Neurosci. 2009 ; 16(8) : 1024-7. https://doi.org/ 10.1016/j.jocn.2008.10.017

4. Wang Y, Nataraj A. Foot drop resulting from degenerative lumbar spinal diseases: clinical characteristics and prognosis. Clin Neurol Neurosurg. 2014 ; 117 : 33-9. https://doi.org/10.1016/ j.clineuro.2013.11.018

5. Peul WC, van Houwelingen HC, van den Hout WB, Brand R, Eekhof JA, Tans JT, et al. Surgery versus prolonged conservative treatment for sciatica. N Engl J Med. 2007 ; 356(22) : 2245-56. https://doi.org/10.1056/nejmoa064039

6. Hawker GA, Mian S, Kendzerska T, French M. Measures of adult pain: Visual Analog Scale for Pain (VAS Pain), Numeric Rating Scale for Pain (NRS Pain), McGill Pain Questionnaire (MPQ), Short-Form McGill Pain Questionnaire (SF-MPQ), Chronic Pain Grade Scale (CPGS), Short Form-36 Bodily Pain Scale (SF-36 BPS), and Measure of Intermittent and Constant Osteoarthritis Pain (ICOAP). Arthritis Care Res (Hoboken). 2011 ; 63 Suppl 11 : S240-52. https://doi.org/10.1002/acr.20543

7. Fairbank JC, Pynsent PB. The Oswestry Disability Index. Spine. 2000 ; 25(22) : 2940-52; discussion 2952. https://doi.org/10. 1097/00007632-200011150-00017
8. Herdman M, Gudex C, Lloyd A, Janssen M, Kind P, Parkin D, et al. Development and preliminary testing of the new five-level version of EQ-5D (EQ-5D-5L). Qual Life Res. 2011 ; 20(10) : 1727-36. https://doi.org/10.1007/s11136-011-9903-x

9. Deyo RA, Cherkin DC, Weinstein J, Howe J, Ciol M, Mulley AG Jr. Involving patients in clinical decisions: impact of an interactive video program on use of back surgery. Med Care. 2000 ; 38(9) : 959-69. https://doi.org/10.1097/00005650-200009000-00009

10. Gugliotta M, da Costa BR, Dabis E, Theiler R, Jüni P, Reichenbach $\mathrm{S}$, et al. Surgical versus conservative treatment for lumbar disc herniation: a prospective cohort study. BMJ Open. 2016; 6(12): e012938. https://doi.org/10.1136/bmjopen-2016-012938

11. Gibson JN, Waddell G. Surgical interventions for lumbar disc prolapse. Cochrane Database Syst Rev. 2007 ; 24(1) : CD001350. https://doi.org/10.1002/14651858.cd001350.pub3

12. Tang S, Mo Z, Zhang R. Acupuncture for lumbar disc herniation: a systematic review and meta-analysis. Acupunct Med. 2018; 36 : 62-70. https://doi.org/10.1136/acupmed-2016-011332

13. Kim D, Park KS, Lee JH, Ryu WH, Moon H, Park J, et al. Intensive Motion Style Acupuncture Treatment (MSAT) Is Effective for Patients with Acute Whiplash Injury: A Randomized Controlled Trial. J Clin Med. 2020 ; 9(7) : 2079. doi: 10.3390/jcm9072079.

14. Chen D. [Introduction to "motion acupuncture" and target points]. Zhongguo Zhen Jiu 2016 ; 36(9) : 941-4. https://doi. org/10.13703/j.0255-2930.2016.09.014

15. Aono H, Iwasaki M, Ohwada T, Okuda S, Hosono N, Fuji T, et al. Surgical outcome of drop foot caused by degenerative lumbar diseases. Spine. 2007 ; 32(8) : E262-6. https://doi.org/10.1097/ 01.brs.0000259922.82413.72

16. Ruiz-Muñoz M, Cuesta-Vargas AI. Electromyography and sonomyography analysis of the tibialis anterior: a cross sectional study. J Foot Ankle Res. 2014 ; 7(1) : 11. https://doi.org/10. $1186 / 1757-1146-7-11$

17. Vargas-Prada S, Coggon D. Psychological and psychosocial determinants of musculoskeletal pain and associated disability. Best Pract Res Clin Rheumatol. 2015 ; 29(3) : 374-90. https://doi.org/10.1016/j.berh.2015.03.003

18. Dhond RP, Kettner N, Napadow V. Neuroimaging acupuncture effects in the human brain. J Altern Complement Med. 2007 ; 13(6) : 603-16. https://doi.org/10.1089/acm.2007.7040 
19. Xiang A, Cheng K, Shen X, Xu P, Liu S. The Immediate Analgesic Effect of Acupuncture for Pain: A Systematic Review and Meta-Analysis. Evid Based Complement Alternat Med. 2017 ; 2017 : 3837194. https://doi.org/10.1155/2017/3837194

20. Shin JS, Ha IH, Lee J, Choi Y, Kim MR, Park BY, et al. Effects of motion style acupuncture treatment in acute low back pain patients with severe disability: a multicenter, randomized, controlled, comparative effectiveness trial. Pain. 2013 ; 154(7) : 1030-7. https://doi.org/10.1016/j.pain.2013.03.013 